\title{
Assessment of Molecular Variation within 'Raleigh' St. Augustinegrass using Amplified Fragment Length Polymorphism Markers
}

\author{
Jennifer A. Kimball, M. Carolina Zuleta, and Matthew C. Martin \\ Department of Crop Science, Box 7620, North Carolina State University, \\ Raleigh, NC 27695-7620
}

Kevin E. Kenworthy

Department of Agronomy, Box 110500, University of Florida, Gainesville, FL 32611-0500

\section{Ambika Chandra \\ Texas AgriLife Research, Texas A\&M System, 17360 Coit Road, Dallas, TX 75252}

\section{Susana R. Milla-Lewis ${ }^{1}$ \\ Department of Crop Science, Box 7620, North Carolina State University, Raleigh, NC 27695-7620}

Additional index words. Stenotaphrum secundatum, genetic diversity, cultivar identification, molecular markers, warm-season grasses, vegetatively propagated species, turfgrass

\begin{abstract}
St. augustinegrass [Stenotaphrum secundatum (Walt.) Kuntze] is a popular turfgrass in the southern United States as a result of its superior shade tolerance and relatively low input requirements. However, it is the least cold-tolerant of commonly used warm-season turfgrass species. 'Raleigh', released in 1980, has superior cold tolerance and is adapted and widely used in U.S. Department of Agriculture hardiness zones 8 to 9. More than 25 years after its release, 'Raleigh' is still the industry's standard in terms of cold tolerance. However, the original foundation and breeder stock fields of the cultivar have been lost, placing the integrity of the cultivar at risk. The objectives of this study were to investigate whether current 'Raleigh' production fields across the southern United States are true to the original source. In this study, 15 amplified fragment length polymorphism (AFLP) primer combinations were used to assess levels of genetic variability among three original stocks of 'Raleigh' and 46 samples obtained from sod farms and universities in six states. Genetic similarities among the original stocks were $S_{i j}=1$, whereas similarities between this group and all other samples ranged from 0.24 to 1.0. Results based on cluster analysis, principal coordinate analysis, and analysis of molecular variance (AMOVA) revealed separation between original stocks of 'Raleigh' and some commercial samples. Results from this study offer further evidence that molecular markers provide a useful and powerful technique for identity preservation of clonally propagated cultivars and the detection of genetic variants in sod production fields and turfgrass breeding programs.
\end{abstract}

St. augustinegrass [Stenotaphrum secundatum (Walt.) Kuntze] is a coarse-textured, warm-season, perennial turfgrass species well adapted for home lawns and commercial landscapes across the southern United States and upward into the southern regions of the

Received for publication 15 Sept. 2011. Accepted for publication 1 Dec. 2011.

We thank John Cosper for help collecting sod samples from Texas, Roberto Gurgel for providing original stock of Palmetto, and all the sod farmers in Florida, Georgia, Louisiana, North Carolina, South Carolina, and Texas who generously contributed samples of 'Raleigh' and 'Palmetto' for this study.

${ }^{1}$ To whom reprint requests should be addressed; e-mail susana_milla-lewis@ncsu.edu. transition zone. The species is commonly used in the sod industry for its superior shade tolerance and stoloniferous growth habit (Busey, 2003). A lack of cold tolerance, however, restricts the widespread use of st. augustinegrass in the northern range of its adaptation. In the early 1980s, the cultivar Raleigh was released for its superior cold tolerance (Busey et al., 1982) and has since become the industry's standard for this trait. 'Raleigh' was collected from a home lawn in Raleigh, NC, in 1964, and released (NC Foundation Seed Producers certified number 101649) by Dr. W.B. Gilbert at North Carolina State University in 1980 (Bateman, 1980). During that year, Dr. Gilbert planted foundation fields of Raleigh at the North Carolina State University (NCSU) Faculty Club Research Laboratory (Raleigh, NC) and four North Carolina sod farms. Severe winterkill during an unusually cold winter in 1981 destroyed all of the foundation material (including NCSU's breeder stocks) except from one location, Oakland Plantation Sod Farm (Council, NC). Harvest of foundation stock of 'Raleigh' began in July 1982 and continued until 1999. In 2000, this last foundation field was terminated as a result of poor appearance. Currently, only registered and certified fields of 'Raleigh' remain in production.

Vegetative propagation of turfgrass cultivars ensures uniformity and predictable performance. The quality and integrity of commercial cultivars can be compromised by the presence of off-types, which often arise in clonally propagated cultivars through random somatic mutation, contamination by unintended cultivars/genotypes, and seedling infestation (Anderson et al., 2001; CaetanoAnolles, 1998a). Elevated mutation rates and contamination issues have been reported in several clonally propagated crops including agaves (Agavaceae sp.) (Infante et al., 2006), bermudagrass (Cynodon sp.) (Anderson et al., 2001; Caetano-Anolles, 1998b), grapevines (Vitis vinifera L.) (Dangl et al., 2001), and tea plants [Camellia sinesis (L.)] (Singh et al., 2004). Minor mutations that occur in the process of asexual reproduction often produce morphologically indistinguishable changes. Although some changes may be phenotypically unidentifiable, they could still affect turfgrass performance and reduce the acceptance of the cultivar. If off-types go undetected, the vegetative nature of production can perpetuate the genetic variants and lead to very large contamination problems (Busey, 2009).

Many approaches to assess variability in clonal plants have been reported, but indistinguishable morphology has been difficult to characterize. Molecular markers have the ability to detect genetic variation and provide a reliable method to ensure the integrity of a cultivar's genetic constitution. Anderson et al. (2001) found that different sources of common ' $U-3$ ' bermudagrass separated into unique unweighted pair group method with arithmetic averaging (UPGMA) clusters according to DNA amplification fingerprinting primers. Molecular markers can provide an empirical estimate of allelic diversity to determine how similar varieties are to one another, which not only aids in maintaining the integrity of the genotype, but also in pursuing varietal protection in the market. Simple sequence repeats (SSRs) are highly informative markers that can provide excellent resolution of genotypic variation within and between species (Powell et al., 1996). In st. augustinegrass, however, SSR marker development has been limited to only a few studies transferring a limited number of SSRs from other crops such as buffelgrass [Pennisetum ciliare (L.) Link] (Genovesi et al., 2009), maize (Zea mays L.), and rice (Oryza sativa) (Kimball et al., 2010). AFLP (Vos et al., 1995) is a multilocus molecular marker technique that is capable of amplifying 
numerous loci and has high levels of polymorphism. AFLPs are commonly used for assessing genetic diversity and population structure in species with little to no sequence information (i.e., st. augustinegrass) because they do not require prior sequence information to adequately evaluate the genetic diversity of a species or group of species (Meudt and Clarke, 2007). Other benefits of AFLPs include their high resolution and reproducibility.

More than 25 years after its release, 'Raleigh' is still widely used and considered the industry's standard for cold tolerance in st. augustinegrass. Therefore, it is important to investigate whether st. augustinegrass currently produced across the southern United States and sold as 'Raleigh' is genetically true to the original stock released in the early 1980s. Molecular markers can be a valuable tool for plant identification and preserving this highly valued cultivar. The objective of this study was to assess the genetic variability of 'Raleigh' st. augustinegrass produced across the southern United States using AFLP markers.

\section{Materials and Methods}

Plant materials and DNA extraction. In total, 49 samples of 'Raleigh' were evaluated in this study (Table 1). 'Raleigh' samples were obtained from 40 sod farms in six states (Florida, Georgia, Louisiana, North Carolina, South Carolina, and Texas) across the southern United States as well as samples from the germplasm collections at NCSU, Texas AgriLife Research-Dallas, Louisiana State University, the University of Florida, and two other sites in North Carolina. Three original stocks of 'Raleigh' were used in this study: two samples from the original collection site for 'Raleigh' (lat. $+35^{\circ} 47^{\prime} 34.55^{\prime \prime} \mathrm{N}$, long. $\left.-78^{\circ} 40^{\prime} 54.77^{\prime \prime} \mathrm{W}\right)$ and one sample from a registered field at Oakland Plantation, Council, NC. For commercial sample collection in North and South Carolina, a 2-inch plug was taken from 'Raleigh' production/sod fields with uniform appearance and no evidence of contamination. Samples from all other states were requested from producers and shipped overnight to North Carolina. The same guidelines were given to all producers for sample collection and shipment. Seven samples of 'Palmetto' (Kirkland and Wagner, 1995), a standard commercial cultivar, were included as a reference of expected diversity within clonally propagated cultivars. 'Palmetto' samples were collected from two states following the same guidelines as for 'Raleigh'. A sample of breeder stock of 'Palmetto' from Sod Solutions (Mt. Pleasant, SC) was included as original stock. After collection (or arrival for samples shipped from other states), plugs were transferred into plastic pots filled with Fafard 4P potting mix (Conrad Fafard Inc., Agawam, MA) and placed in a greenhouse. Plants were mowed biweekly at a 3-inch height and fertilized every 2 weeks with Scotts ${ }^{\circledR}$ Starter Fertilizer (The Scotts Company LLC, Marysville, OH).
Table 1. List of st. augustinegrass 'Raleigh' and 'Palmetto' samples assessed for genetic variability using 143 polymorphic amplified fragment length polymorphism markers and their genetic similarity values with original stocks of 'Raleigh'.

\begin{tabular}{|c|c|c|c|c|}
\hline Sample no. & ID & Cultivar & Supplier ${ }^{2}$ & $\begin{array}{l}\text { Genetic } \\
\text { similarity }^{\mathrm{y}}\end{array}$ \\
\hline 1 & OriginalStock01 & Raleigh & $\begin{array}{l}\text { Original Raleigh } \\
\text { Collection Site 1, } \\
\text { Raleigh, NC }\end{array}$ & - \\
\hline 2 & OriginalStock02 & Raleigh & $\begin{array}{l}\text { Original Raleigh } \\
\text { Collection Site 2, } \\
\text { Raleigh, NC }\end{array}$ & - \\
\hline 3 & OriginalStock03 & Raleigh & $\begin{array}{l}\text { Oakland Plantation, } \\
\text { Council, NC }\end{array}$ & - \\
\hline 4 & $\mathrm{NC} 01$ & Raleigh & $\begin{array}{l}\text { North Carolina } \\
\text { Sod Farm } 1\end{array}$ & 0.83 \\
\hline 5 & $\mathrm{NC} 02$ & Raleigh & $\begin{array}{l}\text { North Carolina } \\
\text { Sod Farm } 2\end{array}$ & 0.97 \\
\hline 6 & $\mathrm{NC} 03$ & Raleigh & $\begin{array}{l}\text { North Carolina } \\
\text { Sod Farm } 3\end{array}$ & 0.90 \\
\hline 7 & $\mathrm{NC} 04$ & Raleigh & $\begin{array}{l}\text { North Carolina } \\
\text { Sod Farm } 4\end{array}$ & 1.00 \\
\hline 8 & $\mathrm{NC} 05$ & Raleigh & $\begin{array}{l}\text { North Carolina } \\
\text { Sod Farm } 5\end{array}$ & 0.97 \\
\hline 9 & $\mathrm{NC} 06$ & Raleigh & $\begin{array}{l}\text { North Carolina } \\
\text { Sod Farm } 6\end{array}$ & 0.97 \\
\hline 10 & $\mathrm{NC} 07$ & Raleigh & $\begin{array}{l}\text { North Carolina } \\
\text { Sod Farm } 7\end{array}$ & 0.43 \\
\hline 11 & $\mathrm{NC} 08$ & Raleigh & $\begin{array}{l}\text { North Carolina } \\
\text { Sod Farm } 8\end{array}$ & 0.86 \\
\hline 12 & $\mathrm{NC} 09$ & Raleigh & $\begin{array}{l}\text { BASF Field Test Site, } \\
\text { Holly Springs, NC }\end{array}$ & 0.97 \\
\hline 13 & $\mathrm{NC} 10$ & Raleigh & $\begin{array}{l}\text { NCSU Old Turf Field } \\
\text { Laboratory, Raleigh, NC }\end{array}$ & 0.97 \\
\hline 14 & $\mathrm{NC} 11$ & Raleigh & $\begin{array}{l}\text { North Carolina State } \\
\text { University, Raleigh, NC }\end{array}$ & 1.00 \\
\hline 15 & $\mathrm{SC} 01$ & Raleigh & $\begin{array}{l}\text { South Carolina } \\
\text { Sod Farm } 1\end{array}$ & 0.71 \\
\hline 16 & $\mathrm{SC} 02$ & Raleigh & $\begin{array}{l}\text { South Carolina } \\
\text { Sod Farm } 2\end{array}$ & 0.28 \\
\hline 17 & $\mathrm{SC} 03$ & Raleigh & $\begin{array}{l}\text { South Carolina } \\
\text { Sod Farm } 3\end{array}$ & 0.88 \\
\hline 18 & $\mathrm{SC} 04$ & Raleigh & $\begin{array}{l}\text { South Carolina } \\
\text { Sod Farm } 4\end{array}$ & 0.76 \\
\hline 19 & $\mathrm{SC} 05$ & Raleigh & $\begin{array}{l}\text { South Carolina } \\
\text { Sod Farm } 5\end{array}$ & 0.97 \\
\hline 20 & SC06 & Raleigh & $\begin{array}{l}\text { South Carolina } \\
\text { Sod Farm } 6\end{array}$ & 0.91 \\
\hline 21 & SC07 & Raleigh & $\begin{array}{l}\text { South Carolina } \\
\text { Sod Farm } 7\end{array}$ & 0.93 \\
\hline 22 & TX01 & Raleigh & Texas Sod Farm 1 & 0.83 \\
\hline 23 & TX02 & Raleigh & Texas Sod Farm 2 & 0.94 \\
\hline 24 & TX03 & Raleigh & Texas Sod Farm 3 & 1.00 \\
\hline 25 & TX04 & Raleigh & Texas Sod Farm 4 & 0.94 \\
\hline 26 & TX05 & Raleigh & Texas Sod Farm 5 & 0.27 \\
\hline 27 & TX06 & Raleigh & Texas Sod Farm 6 & 0.94 \\
\hline 28 & TX07 & Raleigh & Texas Sod Farm 7 & 1.00 \\
\hline 29 & TX08 & Raleigh & Texas Sod Farm 8 & 0.94 \\
\hline 30 & TX09 & Raleigh & Texas Sod Farm 9 & 0.82 \\
\hline 31 & TX10 & Raleigh & Texas Sod Farm 10 & 1.00 \\
\hline 32 & TX11 & Raleigh & Texas Sod Farm 11 & 0.24 \\
\hline 33 & TX12 & Raleigh & Texas Sod Farm 12 & 0.29 \\
\hline 34 & TX13 & Raleigh & Texas Sod Farm 13 & 1.00 \\
\hline 35 & TX14 & Raleigh & Texas Sod Farm 14 & 0.28 \\
\hline 36 & TX15 & Raleigh & Texas Sod Farm 15 & 1.00 \\
\hline 37 & TX16 & Raleigh & Texas Sod Farm 16 & 1.00 \\
\hline 38 & TX17 & Raleigh & Texas Sod Farm 17 & 0.69 \\
\hline 39 & TX18 & Raleigh & Texas Sod Farm 18 & 0.28 \\
\hline 40 & TX19 & Raleigh & Texas Sod Farm 19 & 0.94 \\
\hline 41 & TX20 & Raleigh & Texas Sod Farm 20 & 1.00 \\
\hline 42 & TX21 & Raleigh & Texas Sod Farm 21 & 0.26 \\
\hline 43 & TX22 & Raleigh & $\begin{array}{l}\text { Texas AgriLife, } \\
\text { Dallas, TX }\end{array}$ & 0.97 \\
\hline 44 & FL01 & Raleigh & Florida Sod Farm 1 & 0.94 \\
\hline 45 & FL02 & Raleigh & $\begin{array}{l}\text { University of Florida, } \\
\text { Gainesville, FL }\end{array}$ & 0.93 \\
\hline 46 & GA01 & Raleigh & Georgia Sod Farm 1 & 0.93 \\
\hline
\end{tabular}


Table 1. (Continued) List of st. augustinegrass 'Raleigh' and 'Palmetto' samples assessed for genetic variability using 143 polymorphic amplified fragment length polymorphism markers and their genetic similarity values with original stocks of 'Raleigh'.

\begin{tabular}{llllc}
\hline Sample no. & \multicolumn{1}{c}{ ID } & Cultivar & \multicolumn{1}{c}{ Supplier $^{2}$} & $\begin{array}{c}\text { Genetic } \\
\text { similarity }\end{array}$ \\
\hline 47 & LA01 & Raleigh & Louisiana Sod Farm 1 \\
48 & LA02 & $\begin{array}{l}\text { Raleigh } \\
\text { Raleigh }\end{array}$ & $\begin{array}{l}\text { Louisiana Sod Farm 2 } \\
\text { Louisiana State University, } \\
\text { Baton Rouge, LA } \\
\text { Sod Solutions, Mt. }\end{array}$ & 0.94 \\
50 & LA03 & Palmetto & 0.81 \\
51 & OriginalPT01 & Pleasant, SC & - \\
52 & PT01 & Palmetto & North Carolina Sod Farm 1 & 0.97 \\
53 & PT02 & Palmetto & North Carolina Sod Farm 2 & 0.94 \\
54 & PT03 & Palmetto & North Carolina Sod Farm 3 & 1.00 \\
55 & PT04 & Palmetto & North Carolina Sod Farm 4 & 1.00 \\
56 & PT05 & Palmetto & North Carolina Sod Farm 5 & 1.00 \\
& PT06 & Palmetto & University of Florida, & 0.97 \\
\hline
\end{tabular}

${ }^{\mathrm{z}}$ Names of farms are not disclosed to protect the business interests of the owners.

${ }^{\mathrm{y}}$ Listed genetic similarity values were calculated as the average between each sample and the three original stocks of 'Raleigh' for samples 4 through 49 and between each sample and the original stock of 'Palmetto' for samples 51 through 56 .

Table 2. Standard statistics for 15 amplified fragment length polymorphism primer combinations used to study molecular variability within st. augustinegrass cultivars Raleigh and Palmetto.

\begin{tabular}{lcccc}
\hline $\begin{array}{l}\text { Primer } \\
\text { combination }\end{array}$ & $\begin{array}{c}\text { Total no. of } \\
\text { DNA fragments }\end{array}$ & $\begin{array}{c}\text { No. of polymorphic } \\
\text { fragments }\end{array}$ & $\begin{array}{c}\text { Percent polymorphic } \\
\text { fragments }\end{array}$ & PIC \\
\hline E32M47 & 87 & 12 & $14 \%$ & 0.21 \\
E34M49 & 85 & 14 & $16 \%$ & 0.21 \\
E35M47 & 101 & 11 & $11 \%$ & 0.23 \\
E35M49 & 75 & 13 & $17 \%$ & 0.20 \\
E36M54 & 56 & 2 & $4 \%$ & 0.17 \\
E37M56 & 87 & 14 & $16 \%$ & 0.21 \\
E38M47 & 95 & 10 & $11 \%$ & 0.26 \\
E38M51 & 65 & 9 & $14 \%$ & 0.10 \\
E46M57 & 72 & 7 & $9 \%$ & 0.09 \\
E39M49 & 63 & 5 & $8 \%$ & 0.18 \\
E41M47 & 97 & 5 & $5 \%$ & 0.23 \\
E41M60 & 60 & 9 & $15 \%$ & 0.13 \\
E44M47 & 80 & 7 & $9 \%$ & 0.06 \\
E46M52 & 69 & 14 & 11 & 0.20 \\
E46M54 & 73 & 143 & - & 0.21 \\
Total & 1166 & 9 & 0.12 & 0.18 \\
Average & 78 & 2 & 0.04 & 0.06 \\
Minimum & 56 & 14 & 0.20 & 0.26 \\
Maximum & 101 & & &
\end{tabular}

$\mathrm{PIC}=$ polymorphic information content.

For DNA extraction, four young unopened leaves were collected from each plant and bulked together. DNA was extracted using the CTAB method of Stein et al. (2001) with the modification that a Fast Prep ${ }^{\circledR}$ FP120 (Qbiogene, Carlsbad, CA) machine was used to grind the tissue. DNA was quantified using a Hoefer fluorometer (Hoefer Scientific Instruments, San Francisco, CA). After quantification, all samples were diluted to $25 \mathrm{ng} \cdot \mu \mathrm{L}^{-1}$ for AFLP analysis and stored at $4{ }^{\circ} \mathrm{C}$.

Amplified fragment length polymorphism fingerprinting. All AFLP reactions were made according to Milla et al. (2005). After amplification, AFLP fragments were denatured at $94{ }^{\circ} \mathrm{C}$ and separated by polyacrylamide gel electrophoresis on a LI-COR 4300 DNA Analyzer Sequencer (LI-COR Biosciences, Lincoln, NE) on $25-\mathrm{cm} 8 \% v / v$ denaturing polyacrylamide gels. Fifteen AFLP primer combinations (PCs) were selected for screening all genotypes. To evaluate the reproducibility of the banding patterns and allele, and $\mathrm{F}_{\mathrm{an}}$ is the frequency of the nonamplified allele (Geuna et al., 2003).The MI was calculated as described by Varshney et al. (2007) as MI $=$ PIC $\times n \times \beta$ where $n$ is the total number of amplified fragments per $\mathrm{PC}$ and $\beta$ is the proportion of polymorphic fragments. Genetic similarity was calculated as $\mathrm{S}_{\mathrm{ij}}=2 \mathrm{~N}_{\mathrm{ij}} /\left(\mathrm{N}_{\mathrm{i}}+\mathrm{N}_{\mathrm{j}}\right)$, where $\mathrm{N}_{\mathrm{ij}}$ is the number of shared bands between genotypes $i$ and $j$ and $\mathrm{N}_{\mathrm{i}}$ and $\mathrm{N}_{\mathrm{j}}$ are the number of total bands found in genotypes $\mathrm{i}$ and $\mathrm{j}$, respectively (Dice, 1945). Genetic similarities were calculated using NTSYSpc Version 2.2 (Rohlf, 2000) and subsequently used to build dendrograms using both the UPGMA (Sokal and Michener, 1958) and the neighbor-joining (NJ; Saitou and Nei, 1987) clustering procedures. Mantel tests (Mantel, 1967) were used to test the significance of correlation between the similarity/dissimilarity matrices and the dendrograms in NTSYSpc Version 2.2. To assess the robustness of the cluster analyses, topologies generated by UPGMA and NJ were compared and bootstrapping was performed (Felsenstein, 1985) with 1000 replications using the Phylogenetic Analysis Using Parsimony (*and Other Methods) (PAUP Version 4.0 Beta) software package (Swofford, 1998). Genetic similarities of 'Raleigh' and 'Palmetto' samples were averaged over the one original stocks of 'Raleigh' and 'Palmetto', respectively to assess their genetic relatedness (Table 1). The genetic relationships among genotypes were also assessed by a principal coordinate (PCO) analysis appertaining to the distance matrix using the Dcenter and Eigen functions of NTSYS. The first three resulting principal coordinate scores were plotted for visualization. Additionally, an AMOVA was performed using Arlequin Version 2.001 (Schneider et al., 2002) to assess the significance of the variation partitioned among and within UPGMA clusters.

\section{Results and Discussion}

Fifteen AFLP PCs produced 1066 total DNA fragments ranging in size from 75 to 709 bp. Standard statistics for all PCs are summarized in Table 2. Per PC, the total number of fragments varied from 56 (E36M54) to 101 (E35M47), and the number of polymorphic fragments ranged from two to 14 . A total of 143 clear, unambiguous, polymorphic fragments were scored. PIC values ranged from 0.06 to 0.26 with an average of 0.18 and were comparable to those found in other studies (Milla-Lewis et al., 2010). AFLP PIC values are generally lower than other marker systems because of their dominant nature. Primer combination E38M47 had the highest PIC value indicating that it had the most discriminatory power of the 15 used. The reproducibility of the AFLP technique in this study was extremely high. The two independently generated sets of AFLP fingerprints were $100 \%$ identical. These levels of reproducibility are comparable to those in other AFLP studies (Wu et al., 2004; Zhang et al., 1999). 
Genetic similarity values $\left(\mathrm{S}_{\mathrm{ij}}\right)$ among the three original stocks of 'Raleigh' (original stock 01-03) were 1.00. Genetic similarities between all samples and the original stocks of 'Raleigh' (averaged overall three samples) ranged from 0.24 to 1.00 (Table 1). The average genetic similarity between all 'Palmetto' samples and original 'Palmetto' (OriginalPT 01) was $\mathrm{S}_{\mathrm{ij}}=0.97$ (Table 1). Limited variability was found among 'Palmetto' samples, indicating that varietal protection through patents and certification is working successfully to maintain the integrity of this clonally propagated cultivar.

UPGMA and NJ dendrograms were generated using Dice genetic similarity values. Similar genetic relationships between samples were produced by both methods revealing the same four main clusters in both dendrograms. Only a few minor disparities in topological rearrangements were observed between the two methods. The cophenetic correlation (Mantel test) for UPGMA clustering was very high $(r=0.99)$ indicating that the UPGMA clustering summarized the similarity matrix extremely well and is, therefore, presented here (Fig. 1). The NJ cophenetic correlation was also very high $(r=$ 0.93 ). Bootstrap values for the long branches of the UPGMA tree were mostly greater than 50 , whereas bootstrap values for small branches were generally less than 50 and are not presented here (Fig. 1). High bootstrap support for long branches indicated the topological arrangements of the four main clusters were robust and reliable. The topological arrangements within a cluster, however, were variable and not as strongly supported.

Four unique clusters were generated from UPGMA cluster analysis. The three samples representing the original 'Raleigh selection' (original stock 01-03) are located in Cluster II. Samples in this cluster are $\approx 89 \%$ similar to each other. Only 20\% (10 of 49) of 'Raleigh' samples tested in this study (represented as • in Fig. 1) appear to be genetically identical to original 'Raleigh' stock 03 , the only remaining registered field of 'Raleigh'. Identical samples included those from the original collection site, NCSU genetic stocks, and several samples collected from Texas sod producers. An additional 25 commercial samples are included in Cluster II. Cluster I is the most genetically similar to Cluster II and contains NC 01, SC 04, LA 02, and LA 03.

Cluster III contains all 'Palmetto' accessions and $\mathrm{NC}$ 07. Although NC07 grouped together with 'Palmetto', it is obvious from the dendrogram that this sample is not actually 'Palmetto'. It is more likely that this sample is a different cultivar that is more closely related to 'Palmetto' than 'Raleigh'. A total of $14 \%$ (20 of 143) of the polymorphic bands distinguished 'Palmetto' from the rest of the samples. 'Palmetto' was included in this study to compare the molecular variability of two vegetatively propagated cultivars. 'Palmetto' is not only a more recent release (Kirkland and Wagner, 1995), but it has been appropriately protected in the sense that it was patented and both breeder stock and

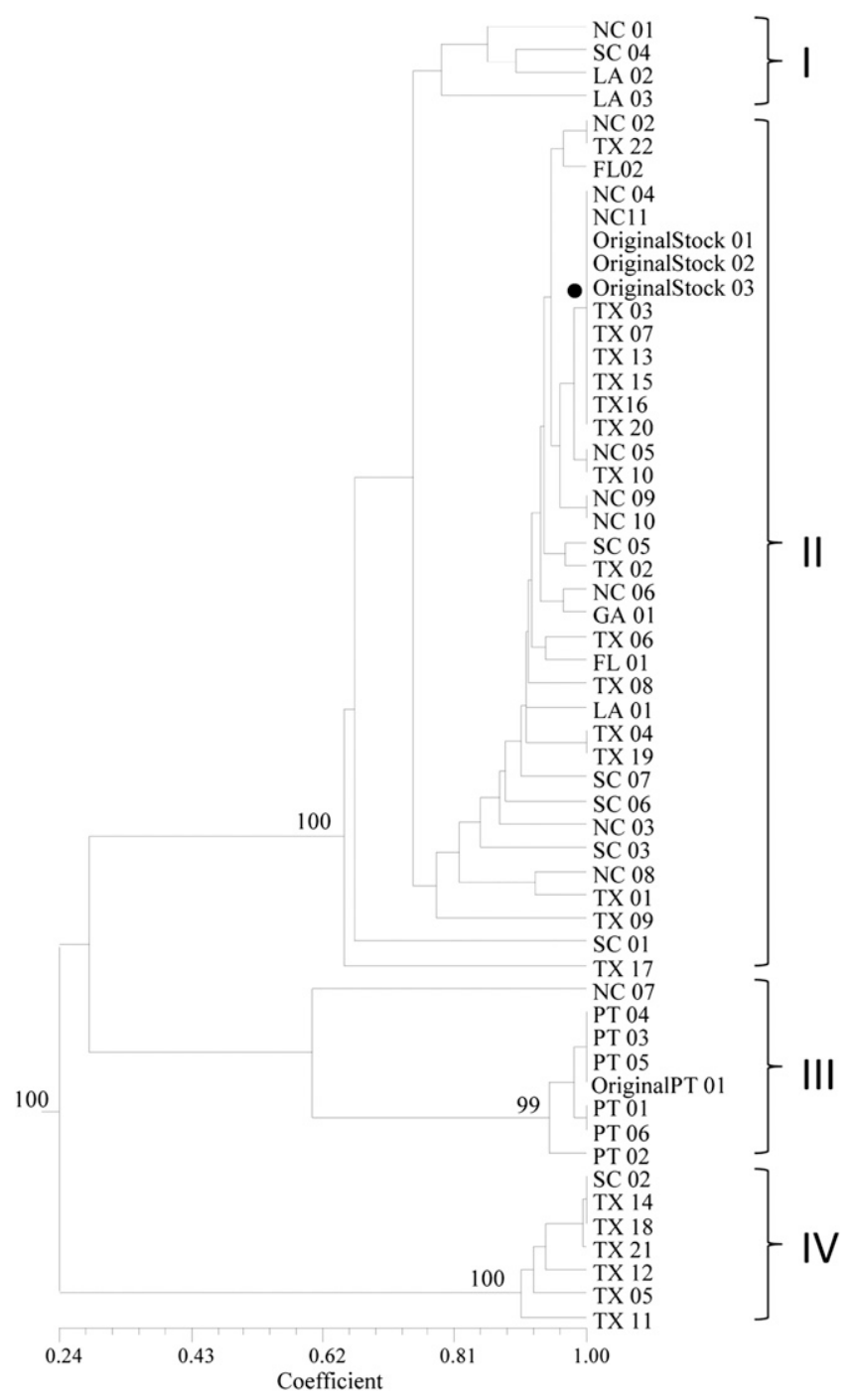

Fig. 1. UPGMA dendrogram of all 49 'Raleigh' and seven 'Palmetto' (PT) samples using 143 AFLP markers. Original stocks of 'Raleigh' and 'Palmetto' are designated as Original Stock 01-03 and Original PT01, respectively. Bootstrap values above $50 \%$ are included in the dendrogram. $\bullet$ denotes samples that are genetically identical to original 'Raleigh' stock 03 , the only registered field of 'Raleigh'. UPGMA = unweighted pair group method with arithmetic averaging; AFLP = amplified fragment length polymorphism.

foundation fields are currently available. 'Palmetto' samples were 97\% genetically similar to one another and grouped together tightly in Cluster III with a high degree of confidence (bootstrap value $=99 \%$ ) indicating not only the genetic uniqueness of the group, but also the limited variability present among these samples (average $S_{i j}=0.97$ ).

Cluster IV is the most genetically dissimilar group in relation to original 'Raleigh' stocks $\left(\mathrm{S}_{\mathrm{ij}}=0.27\right)$. It is $\approx 25 \%$ genetically similar to all other samples. Cluster IV contains six Texas samples and SC02. It should be noted that $55 \%$ (78 of 143) of the polymorphic bands were based on differences between Cluster IV and the rest of the samples. It is important to note that samples in Cluster IV were more genetically distinct from 'Raleigh' than 'Palmetto' samples. This would indicate that these samples diverge enough from original stocks of 'Raleigh' to be considered most likely a different cultivar.
Principal coordinate analysis was also used to assess genetic relationships among all 49 'Raleigh' and seven 'Palmetto' samples (Fig. 2). For all 56 samples, the first three axes of the PCO accounted for $\approx 88 \%$ of the variation with the first, second, and third eigenvalues explaining $66 \%, 12 \%$, and $10 \%$, respectively. Results of the PCO corresponded, for the most part, with those of cluster analysis. Three main groups were present in the PCO, which correlated with UPGMA Cluster III and Cluster IV uniquely and a combination of Clusters I and II.

The partitioning of molecular variation was performed by grouping the samples by their UPGMA clusters (Table 3). Results of the AMOVA revealed variation among the different clusters was significant $(P<$ $0.0001)$ and accounted for the vast majority $(89 \%)$ of the total variation. The withincluster variation component accounted for only $11 \%$ of the total variation and was not 


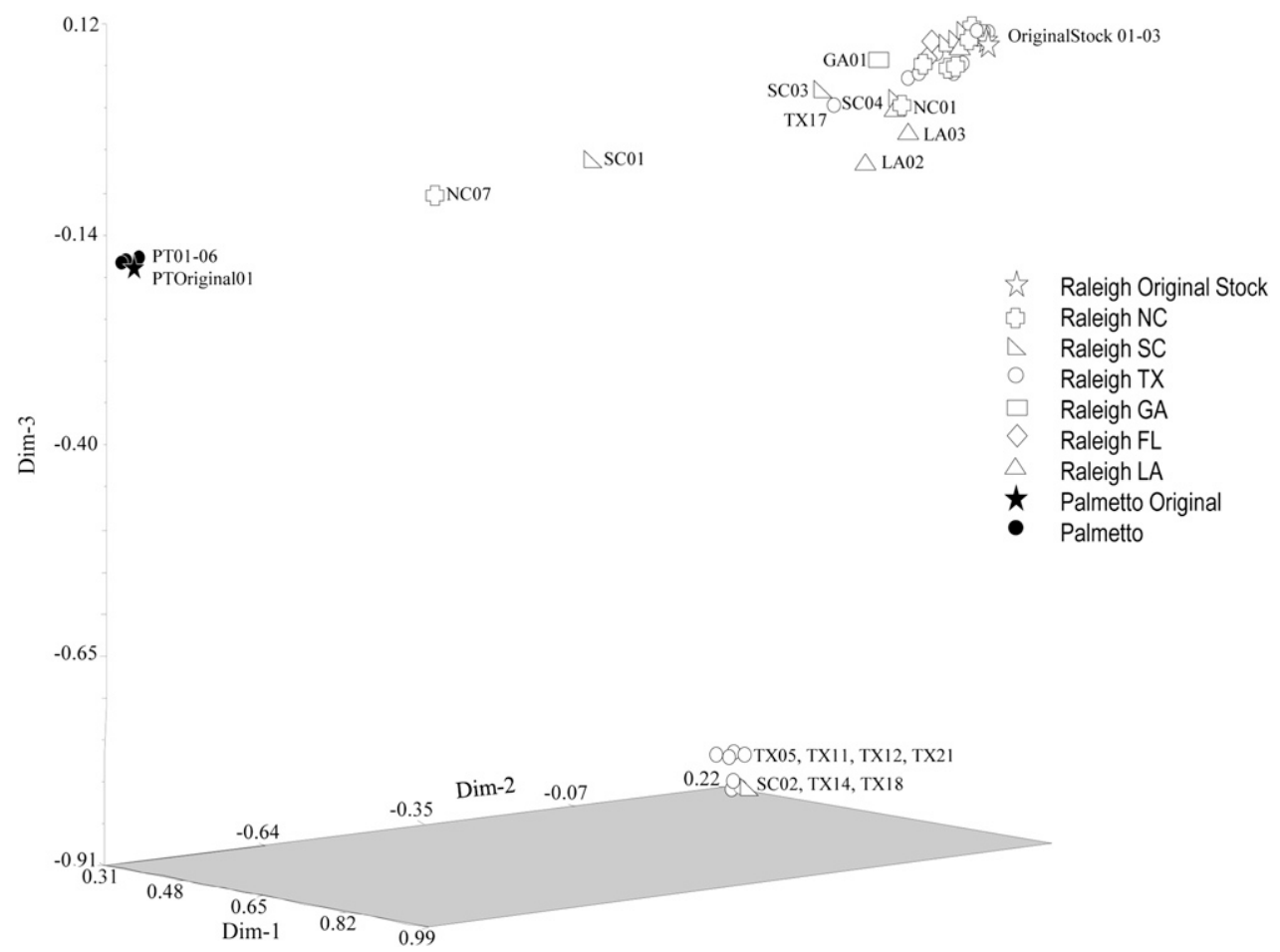

Fig. 2. Principal coordinate plot of 49 'Raleigh' and seven 'Palmetto' samples for the first three principal coordinates estimated with 143 amplified fragment length polymorphism markers.

Table 3. Results of the analysis of molecular variance for st. augustinegrass 'Raleigh' and 'Palmetto' samples grouped by UPGMA Clusters I, II, III, and IV.

\begin{tabular}{lcccc}
\hline Source of variation & df & $\begin{array}{c}\text { Sums of } \\
\text { squares }\end{array}$ & $\begin{array}{c}\text { Variance } \\
\text { components }\end{array}$ & $\begin{array}{c}\text { Variation accounted } \\
\text { for }(\%)\end{array}$ \\
\hline Among UPGMA clusters & 03 & 599.44 & $20.13\left(\mathrm{~V}_{\mathrm{a}}\right)^{* * *}$ & 88.89 \\
Within UPGMA clusters & 53 & 133.39 & $2.52\left(\mathrm{~V}_{\mathrm{b}}\right) \mathrm{Ns}$ & 11.11 \\
Total & 56 & 732.83 & 22.65 & \\
\hline
\end{tabular}

UPGMA = unweighted pair group method with arithmetic averaging.

NS, ***Nonsignificant or significant at $P<0.001$, respectively.

significant. This analysis in conjunction with the highly significant bootstrap values for the long branches of the dendrogram indicate that divergence of individual clusters is significant, whereas divergence or variability within clusters is not as meaningful. Moreover, these results also indicate that there is clear separation of several 'Raleigh' samples (Cluster IV) from the original stocks.

The AFLP analysis in this study provides further evidence that molecular markers afford a useful and powerful technique for preservation of genetic purity in clonally propagated cultivars through the detection of genetic variants in sod production fields and turfgrass breeding programs. Very little information is available regarding the movement of 'Raleigh' sod to and from specific sod farms across the southern United States and, therefore, it is difficult to make assumptions about the gene flow and distribution of genetic variants. Possible causes of the variation present within the off-types may be somatic mutation, the presence of viable seed, contamination through mechanical mixtures, or mislabeling of fields. The low levels of genetic dissimilarity found between original stocks of 'Raleigh' and the majority of samples in Clusters I and II are evidence that these off-types might be the result of genetic mutation (Caetano-Anolles 1998 a, 1998b). It is much more difficult to speculate the contributing factor of the variability found in the South Carolina and Texas samples located in UPGMA Cluster IV.

\section{Conclusions}

This is the first report on the use of molecular markers for genetic identity preservation in a clonally propagated st. augustinegrass cultivar. As more informative molecular markers such as SSRs are developed for st. augustinegrass, relationships between clonally propagated cultivars and genetic variants can be investigated further. These methods might allow for a better understanding of the relationship between 'Raleigh' and the samples for UPGMA Cluster IV. It is possible that Cluster IV samples all trace to a single origin that might be a different cultivar than 'Raleigh'.

This research identifies the importance of protecting genetic material and the need for adhering to strict guidelines for the release, propagation, distribution, and sale of warm-season turfgrasses that are now more commonplace than at the time of 'Raleigh's' release. Modern release mechanisms for newer cultivars developed from universities may involve official cultivar release reviews within respective universities to get an approval for release. Once released, a genotype would be submitted for a plant patent, the cultivar name would be trademarked, and the cultivar would subsequently be licensed to a single producer or multiple producers. The licensee(s) or the releasing institution might require that the cultivar be monitored by a seed certification service and sold only as certified sod. In addition, strict protocols would be followed for propagation to ensure the genetic purity of the cultivar as its production increases and it gets shared with other sod producers. Problems with genetic purity and ensuring that a cultivar is true to type have been issues with several clonally propagated turfgrass species. The inclusion of newer cultivars in certification and other programs designed to protect the cultivar are serving to benefit producers as well as consumers and to ensure long-term cultivar success.

In the past, the only practical system available to maintain the genetic purity of a released cultivar focused on routine phenotypic inspections and production methods, which decreased the likelihood of contamination from off-types. Without some form of mechanism in place to protect the genotype and cultivar name, there is little that can be done to prevent the sale (knowingly or unknowingly) of clonally propagated sod that is not true to the cultivar description. The genetic information developed through this 
research could be a very useful tool for helping to protect clonally propagated turfgrass cultivars in the future.

\section{Literature Cited}

Anderson, M.P., C.M. Taliaferro, D.L. Martin, and C.S. Anderson. 2001. Comparative DNA profiling of U-3 turf bermudagrass strains. Crop Sci. 41:1184-1189.

Bateman, D.R. 1980. Notice to sod producers and growers relative to the naming and release of the new st. augustine cultivar 'Raleigh'. NC Ag. Res. Serv., Raleigh, NC.

Busey, P. 2003. St. augustinegrass, Stenotaphrum secundatum (Walt.) Kuntze, p. 309-330. In: Casler, M.D. and R.R. Duncan (eds.). Biology, breeding, and genetics of turfgrasses. John Wiley \& Sons, Inc., Hoboken, NJ.

Busey, P. 2009. Proliferation and detection of contamination in turfgrass vegetative propagation. Intl. Turfgrass Soc. Res. J. 11:1177-1182.

Busey, P., T. Broschat, and B. Center. 1982. Classification of st. augustinegrass. Crop Sci. 22: 469-473.

Caetano-Anolles, G. 1998a. DNA analysis of turfgrass genetic diversity. Crop Sci. 38:1415-1424.

Caetano-Anolles, G. 1998b. Genetic instability of bermudagrass (Cynodon) cultivars 'Tifgreen' and 'Tifdwarf' detected by DAF and ASAP analysis of accessions and off-types. Euphytica 101:165-173.

Dangl, G., M. Mendum, B. Prins, M. Walker, C. Meredith, and C. Simon. 2001. Simple sequence repeat analysis of a clonally propagated species: A tool for managing a grape germplasm collection. Genome 44:432-438.

Dice, L.R. 1945. Measures of the amount of ecologic association between species. Ecology 26:297-302.

Felsenstein, J. 1985. Confidence limits on phylogenies: An approach using the bootstrap. Evolution 39:783-791.

Genovesi, A., R. Jessup, M.C. Engelke, and B. Burson. 2009. Interploid st. augustinegrass [Stenotaphrum secundatum (Walt.) Kuntze] hybrids recovered by embryo rescue. In Vitro Cell. Dev. Biol. 45:659-666.

Geuna, F., M. Toschi, and D. Bassi. 2003. The use of AFLP markers for cultivar identification in apricot. Plant Breed. 122:526-531.

Infante, D., S. Molina, R. Demey, and E. Gamez. 2006. Asexual genetic variability in Agavaceae determined with inverse sequence-tagged repeats and amplification fragment length polymorphism analysis. Plant Mol. Biol. Rpt. 24. 205-217.

Kimball, J., M. Zuleta, and S.R. Milla-Lewis. 2010. Transferring informative cereal SSRs to warmseason turfgrasses for germplasm characterization and evaluation. Proc. Amer. Soc. Agron Intl. Ann. Mtg., Long Beach, CA. 31 Oct. to 4 Nov.

Kirkland, E. and T. Wagner. 1995. St. augustinegrass 'SS-100'. U.S. Patent 9,395, filed 6 Apr. 1994 and issued 5 Dec. 1995.

Mantel, N.A. 1967. The detection of disease clustering and a generalized regression approach. Cancer Res. 27:209-220.

Meudt, H.M. and A.C. Clarke. 2007. Almost forgotten or latest practice? AFLP applications, analyses and advances. Trends Plant Sci. 12: 106-117.

Milla, S.R., T.G. Isleib, and H.T. Stalker. 2005. Taxonomic relationships among Arachis sect. Arachis species as revealed by AFLP markers. Genome 48:1-11.

Milla-Lewis, S.R., M.C. Zuleta, G.A. Van Esbroeck, K.H. Quesenberry, and K.E. Kenworthy. 2010. Molecular and cytological assessment of genetic diversity in Stenotaphrum germplasm. Proc. Amer. Soc. Agron. Intl. Ann. Mtg., Long Beach, CA. 3 Oct. to 4 Nov.

Powell, W., G.C. Machray, and J. Provan. 1996. Polymorphism revealed by simple sequence repeats. Trends Plant Sci. 1:215-222.

Rohlf, F.J. 2000. NTSYS-PC: Numerical taxonomy and multivariate analysis system, Version 2.2. Exeter Software, Setauket, NY.

Saitou, M. and N. Nei. 1987. The neighbor joining method: A new method for reconstructing phylogenetic trees. Mol. Biol. Evol. 4:406425.

Schneider, S., D. Roessli, and L. Excoffier. 2002. ARLEQUIN Version 2.001: A software for population genetics data analysis. Genetics and Biometry Laboratory, University of Geneva, Switzerland. 19 May 2004. <http://lgb. unige.ch/arlequin/software>.

Singh, M., J. Saroop, and B. Dhiman. 2004. Detection of intra-clonal genetic variability in vegetatively propagated tea using RAPD markers. Biol. Plant. 48:113-115.

Sokal, R.R. and C.D. Michener. 1958. A statistical method for evaluating systematic relationships. Univ. Kansas Sci. Bull. 28:1409-1438.

Stein, N., G. Herren, and B. Keller. 2001. A new DNA extraction method for high-throughput marker analysis in a large-genome species such as Triticum aestivum. Plant Breed. 120:354356.

Swofford, D.L. 1998. PAUP* Phylogenetic analysis using parsimony (*and other methods). Version 4. Sinauer Associates, Sunderland, MA.

Varshney, R.K., K. Chabane, P.S. Hendre, R.K. Aggarwal, and A. Graner. 2007. Comparative assessment of EST-SSR, EST-SNP and AFLP markers for evaluation of genetic diversity and conservation of genetic resources using wild, cultivated, and elite barleys. Plant Sci. 173: 638-649.

Vos, P., R. Hogers, M. Bleeker, M. Reijans, T. van de Lee, M. Hornes, A. Friters, J. Pot, J. Paleman, M. Kuiper, and M. Zabeau. 1995. AFLP: A new technique for DNA fingerprinting. Nucleic Acids Res. 23:4407-4414.

Wu, Y., C. Taliaferro, G. Bai, and M. Anderson. 2004. AFLP analysis of Cynodon dactylon (L.) Pers. var. dactylon genetic variation. Genome 47:689-696

Zhang, L.H., P. Ozias-Akins, G. Kochert, S. Kresovich, R. Dean, and W.W. Hanna. 1999. Differentiation of bermudagrass (Cynodon spp.) genotypes by AFLP analyses. Theor. Appl. Genet. 98:895-902. 